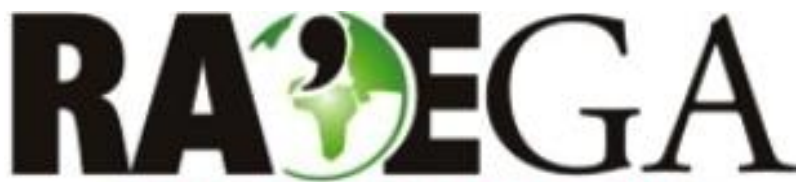

O ESPAÇO GEOGRÁFICO EM ANÁLISE

\title{
CONTROLE ADUANEIRO, USO DO TERRITÓRIO BRASILEIRO E SITUAÇÃO GEOGRÁFICA: O CASO DE NODAL DE FOZ DO IGUAÇU-PR ${ }^{1}$
}

\section{USE OF THE BRAZILIAN TERRITORY, CUSTOMS CONTROL IN NETWORK AND SITUATION OF THE NODAL IN FOZ DO IGUAÇU-PR}

Roberto França²

\section{RESUMO}

Não há nada mais controlado e regulado que a circulação de pessoas e mercadorias. À medida em que avançam as técnicas que dotam as máquinas de maior velocidade, maior controle normativo é exercido. Essas contradições comparecem no controle aduaneiro, que é parte do sistema tributário dos territórios nacionais. Nesse contexto, o Estado é o principal mediador das ações capitalistas através da tributação, que é uma forma de domínio sobre a intensa circulação e sobre as complexas redes de comércio internacional. Para realizar esse desígnio, o Estado constitui territorialidades em rede de nós aduaneiros considerando a intensidade dos fluxos e o volume de capitais envolvidos na circulação. Sob os aspectos técnicos e normativos, estes objetos são cada vez mais densificados, especialmente por tecnologias da informação e normas fiscais. A rede aduaneira é composta por pontos de fronteira, portos, aeroportos, portos secos entre outros nós aduaneiros, em uma topologia poderosa e controladora. Trata-se do poder sobre as riquezas que circulam no país, pois o Estado pratica ações intrínsecas ao seu poder administrativo, especialmente na questão da circulação de riquezas e pessoas, seja para interrupção ou proteção. Trata-se do exercício do poder de política fiscal por parte do Estado dada pelo direito fiscal e aduaneiro, dimensões do poder de tributar. A fim de contribuir para pensar essa realidade, o objetivo deste artigo é analisar a territorialidade aduaneira da Receita Federal do Brasil (RFB) a partir do nodal de Foz do Iguaçu-PR.

PALAVRAS-CHAVE: Rede geográfica; Território aduaneiro; Fronteira; Poder de tributação; Logística

\section{ABSTRACT}

The movement of people and goods is increasingly regulated with advancing techniques. This contradiction appears in the customs control by the state. This control is part of the tax system of national territories and intermedia capitalist actions. It is exercised dominion over the intense circulation and on the complex international trade networks. With this intention, the State builds a customs infrastructure that form territoriality in network nodes customs. Under the technical and regulatory aspects, these objects are increasingly dense, especially information technology and tax rules. The customs network is composed of border points, ports, airports, dry ports and other customs us in a powerful topology and controlling. This is the power over the wealth circulating in the country, as the state practice intrinsic actions to its administrative power, especially on the issue of circulation of wealth and people, whether for switching or protection. It is the exercise of power of fiscal policy by the State, given the tax and customs duty, the power to tax dimensions. In order to contribute to think that reality, the purpose of this article is to analyze the customs territoriality of the Federal Revenue of Brazil from the nodal Foz do Iguaçu, Paraná, Brazil

KEY-WORDS: Geographic network; Customs Territory; Borderland; Taxation Power; Logistics

Recebido em: 26/10/2016

Aceito em: 27/10/2017

1 Esta pesquisa foi fomentada pelo Programa de Apoio ao Pesquisador da Unila (Propesq), promovido conjuntamente pelo Instituto Mercosul de Estudos Avançados (IMEA) e Pró-reitoria de Pesquisa e Pós-graduação (PRPPG), aos quais gostaríamos de aproveitar a oportunidade para agradecer.

\footnotetext{
${ }^{2}$ Universidade Federal da Integração Latino-Americana, UNILA, Foz do Iguaçu/PR, e-mail: roberto.franca@unila.edu.br
} 


\section{INTRODUÇÃO}

A partir da crise sistêmica ocorrida na década de 1970, o capitalismo passou por ajustes estruturais que ficou conhecido como reestruturação produtiva (ALVES, 2007), fulcro de uma reestruturação logística (SILVA JUNIOR, 2009; 2015).

A natureza dessa transformação logística ocorreu tanto nas cadeias de valores (SILVA JUNIOR, 2009; 2012 b), quanto na dinamização do emergente "sistema toyotista" baseado na lean manufacturing ("produção enxuta") e no aumento progressivo da velocidade na movimentação das mercadorias ${ }^{3}$. Esses acontecimentos ajudaram a organizar a "mundialização do capital" (CHESNAIS, 1994; 2001).

Essa profunda transformação demandou novos acordos comerciais, tarifários e aduaneiros na escala mundial. Como consequência, a proteção das fronteiras e o controle aduaneiro de mercadorias, progressivamente, se fortaleceram do ponto de vista técnico e normativo.

O controle aduaneiro é parte do sistema fiscal e tributário dos territórios nacionais, isto é, o exercício de poder sobre os territórios passa por esses controles. Para realizar esse desígnio, o Estado organiza uma rede aduaneira que leva em consideração a intensidade dos fluxos e o volume de capitais envolvidos na circulação.

A aduana é o órgão que fiscaliza os fluxos de comércio exterior. No Brasil a aduana é controlada pela Receita Federal do Brasil (RFB), que está subordinada ao Ministério da Fazenda $(\mathrm{MF})^{4}$.

A estratégia aduaneira baseada na rede formata uma territorialidade específica, que não sobrepõe as demais territorialidades de um Estado nacional, mas que é territorialidade eminente, possibilitando o controle sobre a

\footnotetext{
3 Velocidade dos meios de transportes e das novas tecnologias da informação e comunicações (NTICs) em permanente evolução, juntamente com novas tecnologias logísticas. Estes últimos elementos têm sido negligenciados na análise geográfica.

${ }^{4}$ Para um debate mais aprofundado sobre o território como recurso ver Estudos Territoriais Brasileiros (2004).
}

movimentação de pessoas, bens e serviços. Nesse sentido, a territorialidade "designa a qualidade que o território ganha de acordo com sua utilização ou apreensão pelo ser humano" (SPOSITO, 2009, p. 11).

De acordo com Sack (1986, p. 22), a territorialidade é "a tentativa de um indivíduo ou grupo de afetar, influenciar ou controlar pessoas, fenômenos e relações, através da delimitação e da afirmação do controle sobre uma área geográfica". Nessa perspectiva, pode-se dizer que há uma territorialidade de natureza fiscal e tributária (em rede), a partir da distribuição dos mais diversos objetos técnicos voltados à circulação $^{5}$ e nós logísticos ${ }^{6}$. Sob os aspectos técnicos e normativos, estes objetos são cada vez mais densificados, especialmente por tecnologias da informação e normas fiscais e tributárias.

A rede aduaneira brasileira é composta por pontos de fronteira, portos, aeroportos, portos secos entre outros nós aduaneiros em uma topologia que acompanha a rede urbana brasileira do ponto de vista hierárquico, como demonstraremos doravante. Trata-se do poder sobre as riquezas que circulam no território, seja para interrupção dos fluxos ou na suposta proteção dos cidadãos. No entanto, em realidade é a execução do poder de política fiscal por parte do estado dada pelo direito fiscal e aduaneiro (LIMA \& SÉLLOS-KNOERR, 2014), dimensões do poder de tributar.

Do ponto de vista jurídico-normativo e institucional "o território aduaneiro compreende

\footnotetext{
${ }^{5}$ A circulação é "a produção do espaço em movimento por intermédio dos sistemas de movimentos, de um sistema técnico (característico de cada período) e de normas" (SILVA JUNIOR, 2012 a, p. 412).

6 Para Braga (2012, p. 2), a "logística interfere no desequilíbrio da relação entre possibilidades de uso do território e usos efetivos e uma de suas expressões mais contundentes são os nós logísticos, que ajudam a discriminar fluxos hegemônicos e não hegemônicos e a caracterizar o uso do território". Sendo que "os nós logísticos (portos secos, centrais de distribuição, terminais portuários, plataformas logísticas, entre outros) figuram como equipamentos especialmente concebidos e normatizados para concentrar e redistribuir mercadorias no território" (BRAGA, 2012, p. 7).
} 
todo o território nacional" (BRASIL, $2009 \mathrm{a}^{7}$ ) e é dividido em zona primária, que é "área terrestre ou aquática, contínua ou descontínua, nos portos alfandegados; a área terrestre, nos aeroportos alfandegados; e área terrestre, que compreende os pontos de fronteira alfandegados"; e zona secundária, "que compreende a parte restante do território aduaneiro, nela incluídas as águas territoriais e o espaço aéreo" (BRASIL, 2009 a) . Mostra-se aqui a tentativa de ter, no território, a expressão máxima de poder legítimo (e monopólico) sobre a fiscalização e obtenção de dividendos provenientes da circulação do capital em todas as suas formas.

Evidentemente que a norma jurídica não encerra a norma lato sensu, e, podemos afirmar, que a configuração extrapola (não no sentido físico/solo) a contiguidade e se territorializa na forma de rede, por meio da qual o estado efetivamente tenta exercer o máximo controle. A questão central reside em realizar o controle aduaneiro e evidenciar o território como instrumento legítimo do poder do Estado. Contudo, geograficamente, é fundamental reconhecer que o território nacional não é um todo aduaneiro, mas está representada na rede aduaneira, um tipo de rede geográfica ${ }^{8}$, responsável pela formação de territorialidades fiscalizadas e vigiadas, estrategicamente selecionadas.

7 Trata-se, neste caso, de uma conceituação institucional e jurídica. O termo "território aduaneiro" fundamenta o Decreto no 6.759, de 5 de fevereiro de 2009 (a), que regulamenta a administração das atividades aduaneiras, e a fiscalização, o controle e a tributação das operações de comércio exterior. $\mathrm{O}$ que estamos propondo a fazer neste artigo é uma crítica a essa noção enquanto não correspondente à categoria território na Geografia contemporânea

8 Partimos da visão de Lobato Corrêa (2012, p. 200) rede geográfica o conjunto de localizações humanas articuladas entre si por meio de vias e fluxos. Nesse sentido, ela constitui caso particular de rede em geral, esta forma que advém da topologia (...). As redes geográficas são redes sociais espacializadas. São sociais em virtude de serem construções humanas, elaboradas no âmbito de relações sociais de toda ordem, envolvendo poder e cooperação, além daquelas de outras esferas da vida.
A aduana brasileira vem sendo interiorizada a partir do litoral até os limites internacionais terrestres, desde a colonização portuguesa. Os nós aduaneiros vão sendo distribuídos racionalmente pelo território a fim de operacionalizar o controle dos fluxos de mercadorias.

A fim de contribuir para pensar essa realidade, o objetivo deste artigo é analisar a territorialidade aduaneira, em rede, da RFB, a partir do nodal de Foz do Iguaçu, considerando que nodais são "lugares especializados que são resultados diretos da circulação" (HUERTAS, 2013, p. 207). Huertas entende, em relação aos nodais, que "em todos os casos ocorre uma espécie de 'nexo territorial', consubstanciado pela conjugação entre a capacidade dos agentes instalados condicionar arranjos territoriais em todas as escalas". Esses são os agentes ligados ao transporte de mercadorias, que tendem a concentrar o movimento em alguns pontos privilegiados e dotados de infraestrutura. Com essa proposta de discussão, concordamos com Huertas (2013, p. 209) que "os nodais são arenas que proporcionam o alargamento de atuação territorial dos agentes do circuito superior", que preferimos chamar simplesmente de agentes corporativos $^{9}$.

Deste modo, apresentaremos a problemática territorial dos referidos nós aduaneiros, suas formas de organização e controle dos fluxos de comércio exterior. Este controle traz, a reboque, o anseio por mais fluidez territorial, pois normas são produzidas associadas às novas técnicas. A ideia é controlar sem perder a velocidade nas operações, pois trata-se de demanda capitalista, ao mesmo tempo em que o estado estabelece o poder na

\footnotetext{
9 Huertas (2013, p. 217 - 218) ainda propõe uma classificação nodal, colocando o "ponto nodal de Foz do Iguaçu - Mercosul" como de "terceiro nível", "composto pelos 'nodais secundários monofuncionais', cuja tipologia pode estar relacionada à especialização produtiva (circuito espacial de produção petrolífera ou circuitos espaciais de produção agropecuária), à situação geográfica (acesso fronteiriço ao Mercosul) ou à logística do comércio atacadista e distribuidor".
} 
formação de territorialidades aduaneiras nos circuitos capitais.

O Estado exerce o monopólio sobre a tributação. Portanto, o território nacional é um território da tributação, do controle dos fluxos produtivos e de serviços. Consequentemente, fiscalizar e tributar são exercícios de poder que fundamenta os Estados desde o século XVIII. Trata-se do "poder de tributar", que está entre os maiores poderes concedidos pela sociedade ao Estado. Perante o capital, os Estados também são "mercados nacionais". Daí o ímpeto controlador e normativo.

Outro fundamento importante a considerar é que não existe a dicotomia entre a dimensão política e a dimensão econômica da circulação ${ }^{10}$. Concordamos plenamente com Gottman que a economia e a política se "emaranham nas engrenagens da circulação". Sendo assim, o que existe são espacialidades que se formam a partir das "necessidades" dos diversos agentes, sendo que os agentes hegemônicos veem o território como recurso e realizam sua política territorial para viabilizar a circulação da mais-valia.

Destarte, pensaremos essa viabilização do território como recurso, a partir do controle aduaneiro feito pela RFB, na forma de territorialidades aduaneiras na perspectiva do território-rede (HAESBAERT, 2007), através do controle dos fluxos e da mobilidade. Entre os propósitos dos processos de territorialização, de acordo com Haesbaert (2007), está o controle através do espaço por conexões e redes (fluxos de pessoas, mercadorias e informações). Nestes objetivos se inserem a lógica das formações de territorialidades fiscais.

$O$ entendimento de Haesbaert em relação à questão do controle, encontra-se em Deleuze. Segundo Deleuze (1992, p. 216), as "sociedades de controle" funcionam por "controle contínuo e comunicação instantânea", não através do disciplinamento, conforme defendia Foucault, mas por novos tipos de

10 Contrariando a tese de Vallaux (1914), distingue a vertente econômica e a política da circulação. sanções. Nesse contexto, se coloca o sistema aduaneiro como norma e infraestrutura.

\section{MATERIAIS E MÉTODOS}

Para a análise da rede aduaneira utilizamos as informações contidas no sítio da RFB, através dos "Dados Econômico-Tributários e Aduaneiros". A preocupação aqui reside na realização de um levantamento das "Unidades de despacho e embarque".

As unidades de despacho jurisdicionam o local de conferência e desembaraço da mercadoria a ser exportada, e, as unidades de embarque, jurisdicionam o local de saída da mercadoria do território nacional. “É a última unidade da RFB que exerce o controle sobre a mercadoria antes de sua saída do País" (BRASIL, 1994).

Entre as unidades descentralizadas responsáveis pelos despachos e embarques estão as Alfândegas da Receita Federal do Brasil (ALF), as Delegacias da Receita Federal do Brasil (DRF) e as Inspetorias da Receita Federal do Brasil (IRF), que utilizaremos para fins de análise e interpretação geográfica, pois a essas unidades compete realizar o despacho e o embarque aduaneiro.

Também utilizamos o segundo volume do estudo intitulado "Redes e fluxos do território: gestão do território" (BRASIL, 2014) realizado pelo Instituto Brasileiro de Geografia e Estatística (IBGE). Este estudo analisa as redes e fluxos do território em seus aspetos imateriais, analisando os fluxos de gestão relacionadas às ordens, hierarquias, informações, poder e dinheiro. Os órgãos públicos também demonstram uma forma de uso do território (SANTOS \& SILVEIRA, 2006) e nos fornecem um modo de interpretar as relações de poder e a organização territorial.

\section{RESULTADOS E DISCUSSÃO}

\subsection{A ADUANA BRASILEIRA}

Ampliando um pouco a problemática apresentada, a aduana brasileira é um órgão sob controle da RFB presente em todo o território nacional, cujo objetivo é controlar a entrada e a saída de mercadorias através de uma rede 
aduaneira. O controle é exercido sobre os fluxos capital-trabalho, viajantes, bens e serviços, além das informações intrínsecas. Esses fluxos, pela natureza "transnacional", visam-se desterritorializados, mas, em realidade, são controlados pelos Estados.

A instituição internacional que estabelece normas alfandegárias é a Organização Mundial Aduaneira (OMA), criada em 1952, e que possui atualmente 180 membros, ou, 98\% do comércio mundial. Essa é condição legítima para o estabelecimento técnico-normativo na organização de padrões de tarifas, "facilitação" e "execução e cumprimento". O próprio termo "facilitação" demonstra a condição "sob controle" dos fluxos, pois trata-se dos mecanismos de negociação para dar mais fluidez ao território, sem que se perca a autoridade sobre o movimento de pessoas, mercadorias e informações. Nesse caso, "facilitação" e "controle" não são pares dialéticos, pois são elementos de uma geopolítica do controle dos fluxos. Para uma ideia geral sobre o papel normativo da OMA, listamos aqui os objetivos da instituição:

Promote the security and facilitation of international trade, including simplification and harmonization of Customs procedures $=$ Economic Competitiveness Package; Promote fair, efficient, and effective Revenue collection = Revenue Package; Protect society, public health and safety = Compliance and Enforcement Package; Strategic Goal 4 - Strengthen Capacity Building = Organizational Development Package; Promote information exchange between all stakeholders; Raise the performance and profile of Customs; Conduct Research and Analysis (WCO, 2016).

Trazendo as proposituras da OMA para compreender a rede aduaneira no Brasil, observa-se que as aduanas e portos secos acompanham os principais circuitos do capital, constituindo uma verdadeira territorialidade em rede de nós aduaneiros e logísticos compostos por recursos humanos e técnicas cada vez mais avançadas, além de procedimentos normativos baseados na ideia de "simplificação", mas que na visão econômica significa a redução dos custos de transação. Estes custos representam, em outras palavras, os custos de ordem burocrática que faz parte da estrutura de poder do estado.

Enquanto as empresas se estabelecem a partir de uma solidariedade organizacional (SANTOS, 2004, p. 192), o estado estabelece as estruturas fundamentais do controle dos fluxos. As empresas também controlam fluxos, mas sua prioridade é canalizá-los através de redes técnicas (DIAS, 1995). Esta condição se organiza em uma lógica zonal e uma lógica reticular (HAESBAERT, 2007), formando as territorialidades aduaneiras.

$\mathrm{Na}$ lógica zonal, podemos mencionar as 10 Regiões Fiscais (RF) estabelecidas pela Secretaria da Receita Federal do Brasil (SRF) para fazer a gestão do território e realizar a tributação e controle dos fluxos. As RF são controladas por Superintendências Regionais da Receita Federal do Brasil (SRRF), sendo uma por região ${ }^{11}$.

A localização das unidades descentralizadas tem forte correlação com a hierarquia urbana descrita no estudo do IBGE intitulado "Regiões de Influência das Cidades" (BRASIL, 2007). Mas, como o próprio IBGE nos recorda, a organização territorial administrativa da RFB e a jurisdição de suas unidades descentralizadas "foram estabelecidas pela Portaria RFB no 2.466, de 28.12.2010, e seus Anexos, que posteriormente foram alterados por

\footnotetext{
11 De acordo com o Art. 190 (BRASIL, 2009 b): "Às Superintendências Regionais da Receita Federal do Brasil - SRRF compete, quanto aos tributos e contribuições administrados pela RFB, inclusive os destinados a outras entidades e fundos, no âmbito da respectiva jurisdição, gerenciar o desenvolvimento das atividades de arrecadação, controle e recuperação do crédito tributário, de interação com o cidadão, de comunicação social, de fiscalização, de controle aduaneiro, de tecnologia e segurança da informação, de programação e logística, de gestão de pessoas, de planejamento, avaliação, organização e modernização, bem assim supervisionar as atividades das unidades subordinadas e dar apoio técnico, administrativo e logístico e às subunidades das Unidades Centrais localizadas na região fiscal".
} 
sucessivas Portarias, sendo a última delas, considerando o presente estudo, a Portaria RFB no 381, de 27.03.2013" (BRASIL, 2014).

As unidades descentralizadas estabelecidas hierarquicamente pelas SRRF são as Delegacias (DRF), Alfândegas (ALF), Inspetorias (IRF) e Unidades de atendimento ao contribuinte (agências espalhadas por todo o território nacional) ${ }^{12}$. No total, a RFB possui 97 Delegacias, 26 Alfândegas e 55 Inspetorias. Estas serão os tipos de unidades abordados aqui por se tratarem de órgãos que realizam os despachos e os embarques aduaneiros $\mathrm{O}$ Brasil possui 178 unidades com estas funções, distribuídas em todas as regiões fiscais, conforme detalhamento na tabela 1.

12 De acordo com o Art. 224 (BRASIL, 2012): “Às Delegacias da Receita Federal do Brasil - DRF, à Delegacia Especial da Receita Federal do Brasil de Pessoas Físicas - Derpf, às Alfândegas da Receita Federal do Brasil - ALF e às Inspetorias da Receita Federal do Brasil - IRF de Classes "Especial A", "Especial B" e "Especial C", quanto aos tributos administrados pela RFB, inclusive os destinados a outras entidades e fundos, compete, no âmbito da respectiva jurisdição, no que couber, desenvolver as atividades de arrecadação, controle e recuperação do crédito tributário, de análise dos dados de arrecadação e acompanhamento dos maiores contribuintes, de atendimento e interação com o cidadão, de comunicação social, de fiscalização, de controle aduaneiro, de tecnologia e segurança da informação, de programação e logística, de gestão de pessoas, de planejamento, avaliação, organização, modernização, e, especificamente". 
FRANÇA, R.

USO DO TERRITÓRIO BRASILEIRO, CONTROLE ADUANEIRO EM REDE E SITUAÇÃO DO NODAL DE FOZ DO IGUAÇU-PR

Tabela 1 - Unidades de despacho e embarque da RFB por Região Fiscal

\begin{tabular}{|c|c|c|c|c|c|c|c|c|c|c|c|}
\hline \multirow{2}{*}{$\begin{array}{l}\text { Tipo de } \\
\text { Unidade }\end{array}$} & \multicolumn{10}{|c|}{ Regiões fiscais (RF) } & \multirow{2}{*}{$\begin{array}{l}\text { Total de } \\
\text { unidades }\end{array}$} \\
\hline & $1 \underline{a}$ & 2a & 3a & $4 \underline{a}$ & 5 & $6 \underline{a}$ & 7ạ & $8^{a}$ & 9a & $10^{\mathrm{a}}$ & \\
\hline Delegacias & 7 & 9 & 7 & 7 & 6 & 12 & 8 & 21 & 11 & 9 & 97 \\
\hline Alfândegas & 1 & 4 & 4 & 2 & 2 & 0 & 4 & 4 & 3 & 2 & 26 \\
\hline Inspetorias & 6 & 15 & 0 & 6 & 3 & 1 & 1 & 2 & 9 & 12 & 55 \\
\hline Total & 14 & 28 & 11 & 15 & 11 & 13 & 13 & 27 & 23 & 23 & 178 \\
\hline
\end{tabular}

Fonte: RFB (2015). Elaboração: Roberto França.

Com base no estudo "Redes e fluxos do território" (BRASIL, 2014), que considera as grandes regiões em sua metodologia de análise, podemos estabelecer a territorialidade da SRF do seguinte modo: As SRRF estão localizadas prioritariamente em metrópoles, capitais de estados, exceto Manaus (AM) e Goiânia (GO). Manaus (AM) está subordinada a Belém (PA), cidade onde está localizada a Superintendência da Receita e, portanto, está no mesmo nível hierárquico das demais capitais estaduais da região Norte: Macapá (AP), Rio Branco $(A C)$, Porto Velho (RO), Boa Vista (RR) e Palmas (TO). A região Centro-Oeste também possui uma SRRF, localizada em Brasília (DF). A região Sul possui Superintendências em Curitiba (PR) e Porto Alegre (RS). Nordeste e Sudeste têm três Superintendências, que estão localizadas respectivamente em Fortaleza (CE), Recife (PE) e Salvador (BA); e Rio de Janeiro (RJ), Belo
Horizonte (MG) e São Paulo (SP). O mapa a seguir demonstra a forma de organização territorial a partir da Secretaria da Receita, Superintendências, e as unidades descentralizadas.
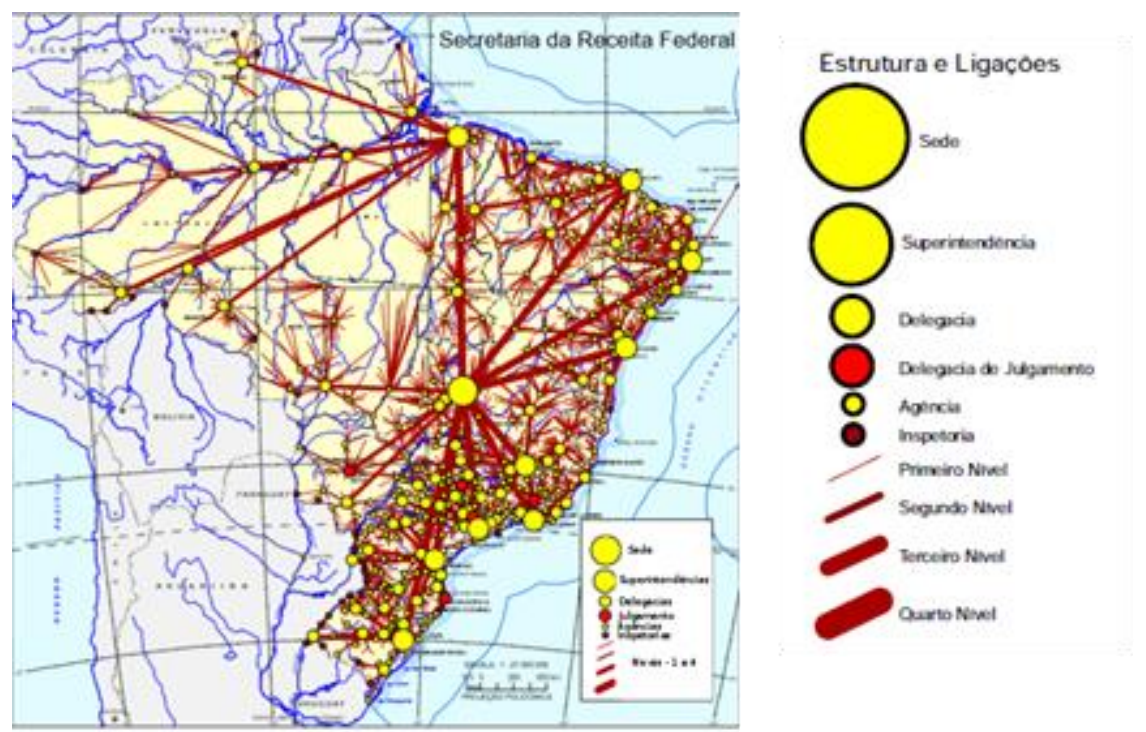

Figura 1 - A Secretaria da Receita Federal do Brasil: Estrutura e Ligações - 2013.Fonte: Extraído de IBGE (2014, folha 39). 


\section{USO DO TERRITÓRIO BRASILEIRO, CONTROLE ADUANEIRO EM REDE E SITUAÇÃO DO NODAL DE FOZ DO IGUAÇU-PR}

$\mathrm{Na}$ hierarquia da instituição, as Delegacias compõem um segundo nível de atuação e estão concentradas no Sudeste, conforme o mapa a seguir (Figura 3). As Delegacias estão localizadas majoritariamente em Capitais Regionais de nível A, de acordo com a classificação adotada pelo IBGE (REGIC, 2008), com algumas exceções, como é o caso de Manaus, uma metrópole, e Ji-Paraná, um Centro Sub-Regional A (BRASIL, 2014). A maior parte das Delegacias estão concentradas em um polígono (em vermelho) que toma a quase a totalidade da região Concentrada, de acordo com a proposta
Santos e Silveira (2006). Há uma segunda grande área de concentração de Delegacias, evidentemente um pouco mais dispersa, mas consideravelmente concentrada.

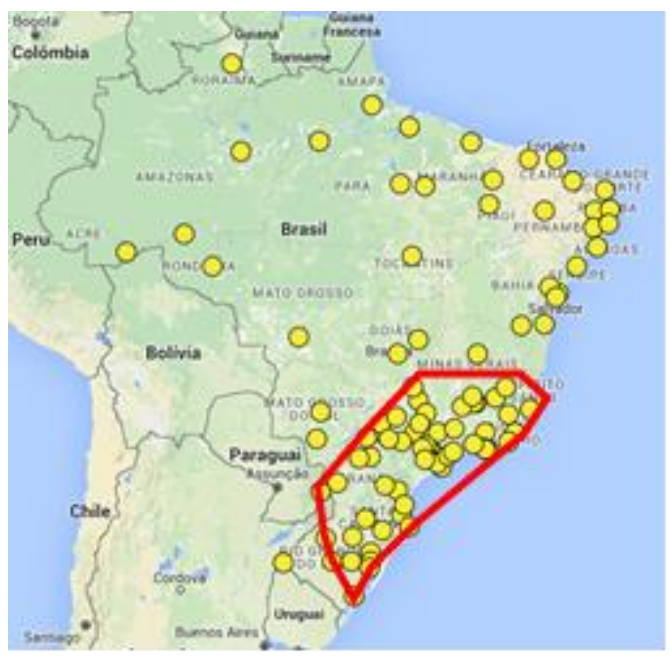

Figura 2 - Delegacias da Receita Federal e concentração territorial. Fonte: RFB (2016). Elaboração própria a partir do GoogleMaps ${ }^{\circledR}$. Na representação, sem escala.

A explicação mais óbvia é o fato dessa área possuir grande densidade populacional e, consequentemente, de fluxos tributários. A tabela 2, a seguir, ajuda a compreender essa situação. A tabela, elaborada a partir das Regiões Fiscais, demonstra que a 1a e a 2a Região Fiscal correspondem a vazios fiscais do ponto de vista do comando e poder de tributar. 
FRANÇA, R.

USO DO TERRITÓRIO BRASILEIRO, CONTROLE ADUANEIRO EM REDE E SITUAÇÃO DO NODAL DE FOZ DO IGUAÇU-PR

Tabela 2 - População por Região Fiscal (estimativa 2015)

\begin{tabular}{|c|c|c|}
\hline $\begin{array}{l}\text { Regiões fiscais } \\
\text { (RF) }\end{array}$ & Estados que compõe a respectiva $\mathrm{RF}$ & $\begin{array}{c}\text { População } \\
\text { (habitantes) }\end{array}$ \\
\hline 8 & São Paulo & 44.396 .484 \\
\hline $6 \underline{a}$ & Minas Gerais & 20.869.101 \\
\hline $7 \underline{a}$ & Espírito Santo e Rio de Janeiro & 20.479 .935 \\
\hline $4 \underline{a}$ & Alagoas, Paraíba, Pernambuco e Rio Grande do Norte & 20.100 .482 \\
\hline $3 \underline{a}$ & Ceará, Maranhã e Piauí & 19.012.728 \\
\hline 9a & Paraná e Santa Catarina & 17.982 .208 \\
\hline $5 \underline{a}$ & Bahia e Sergipe & 17.446 .871 \\
\hline $1 \underline{a}$ & $\begin{array}{l}\text { Distrito Federal, Goiás, Mato Grosso, Mato Grosso do Sul } \\
\text { e Tocantins }\end{array}$ & 16.755 .464 \\
\hline $2^{2}$ & Acre, Amapá, Amazonas, Pará, Rondônia e Roraima & 15.957 .510 \\
\hline $10 \underline{a}$ & Rio Grande do Sul & 11.247.972 \\
\hline Total & & 204.248.755 \\
\hline
\end{tabular}

Fonte: RFB (2016) e IBGE (2015). Elaboração própria.

As DRF desenvolvem e realizam as seguintes atividades: arrecadação; cobrança; atendimento ao contribuinte; fiscalização; controle aduaneiro; segurança de informação; programação; logística; planejamento; organização; modernização dos procedimentos, atividades e recursos humanos. Com essa densidade de atribuições, as Delegacias estão hierarquicamente acima das Alfândegas e Inspetorias. Estas, por suas vezes, passam a deter o comando na ausência de Delegacia próxima. Podemos sintetizar a hierarquia dos órgãos conforme o diagrama a seguir, destacando a estrutura aduaneira da RFB. Nota-se que as
Delegacias, conforme já explicitado, não realizam somente atividades aduaneiras.

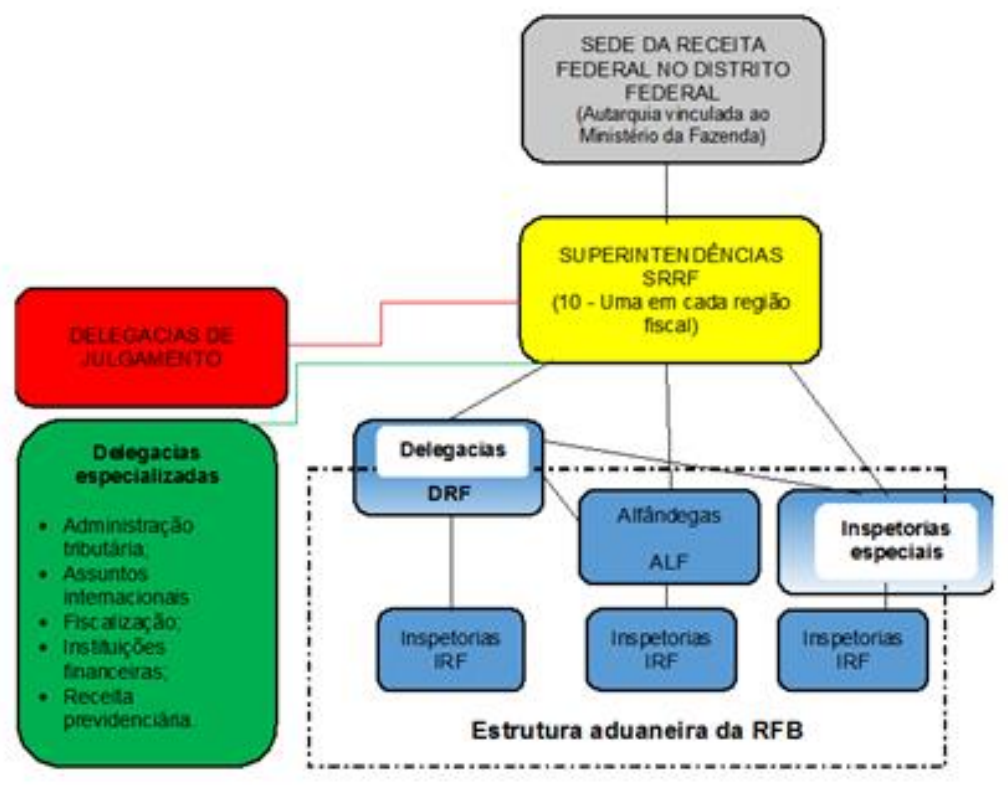

Figura 3 - Hierarquia estrutural da RFB.Fonte: RFB (2016). Elaboração própria. 
Para a realização das atividades aduaneiras, a RFB dispõe Inspetorias pelo território, além das tradicionais Alfândegas já estabelecidas em zonas primárias, estando localizadas nos aeroportos e nos portos marítimos e fluviais. Não há Alfândega em Pontos de Fronteira alfandegados (que também estão em zonas primárias) entre o Brasil com os vizinhos sul-americanos. Aqui não há contradição semântica, pois, Alfândegas e Pontos de Fronteira (alfandegados) são nomes dados a repartições públicas do sistema aduaneiro. A diferença decorre da demarcação geográfica e também pelo fato das Inspetorias serem responsáveis pelo ponto de fronteira quando não há Delegacia.
Tanto a Alfândega quanto o Ponto de Fronteira possuem recintos alfandegados, permitindo que as mercadorias fiquem estocadas antes dos despachos de importação e exportação. 0 mapa a seguir revela a organização territorial da aduana brasileira representada pelas Inspetorias Especiais, Inspetorias e Alfândegas.
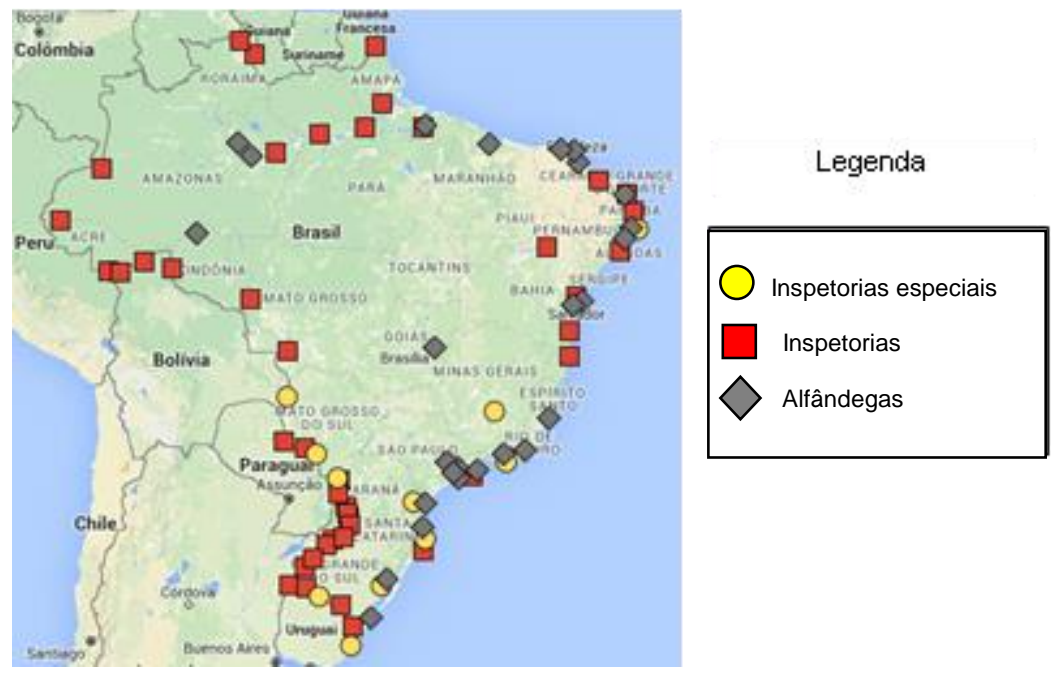

Figura 4 - Inspetorias e alfândegas da RFB.Fonte: RFB (2016). Elaboração própria a partir do GoogleMaps ${ }^{\circledR}$. Na representação, sem escala.

Predominam inspetorias nos limites e adjacências, especialmente no Arco Sul da fronteira brasileira. Também há uma concentração de inspetorias no Mato Grosso do Sul. No Norte, destaca-se o Acre e o vale do Rio Amazonas até sua foz. Há de se salientar a complementaridade às Alfândegas realizada por inspetorias no extenso litoral do Nordeste, além de uma inspetoria no Vale do São Francisco, na grande região fruticultora, agilizando os processos de exportação de frutas e derivados.

Esse é um panorama geral da territorialidade aduaneira no Brasil, uma territorialidade em rede baseada nas mesmas características da hierarquia urbana brasileira, a partir de sua formação socioespacial, concentrada e desigual. Contudo, a rede aduaneira é baseada no interesse do Estado na ocupação do território, procurando estabelecerse em pontos estratégicos, notadamente os principais pontos de entrada e saída do país ${ }^{13}$.

\footnotetext{
13 Não objetivamos neste artigo tratar da elevada permeabilidade da fronteira brasileira e dos fluxos ilícitos que "passam" e que "não passam" pelos principais pontos de fronteira. Também não é objeto aqui tratar dos problemas de corrupção, das deficiências no controle de fronteira humanas e tecnológicas (aviões, barcos, drones, armamentos,
} 


\subsection{A INTERIORIZAÇÃO DAS ADUANAS: PORTOS SECOS COMO NÓS LOGÍSTICOS ADUANEIROS E ELOS DE FLUIDEZ GLOBAIS}

Um porto seco é um terminal interior, podendo ser intermodal ou não, estabelecido em ponto estrategicamente definido, com a capacidade jurídica para o controle aduaneiro. 0 principal objetivo é dar maior velocidade à saída e entrada de mercadorias, contribuindo para a fluidez territorial. Em 1982, a Conferência das Nações Unidas sobre Comércio e Desenvolvimento (UNCTAD) definia porto seco (dry port) como um terminal terrestre "to which shipping companies issue their own import bills of landing for import cargoes assuming full responsibility of costs and conditions and from which shipping companies issue their own bills of landing for export cargoes" (UNCTAD, 1991, p. 2).

É visto, portanto, que a própria demanda internacional por circulação e trocas tende a criar novos ordenamentos cada vez mais normativos e normados a fim de estabelecer maior previsibilidade dos processos e da planificação, favorável às firmas. As normas em nome da velocidade da circulação fusionam, ainda mais, o território e o mercado, promovendo interações "estruturadoras da realidade" (SANTOS, 2004, pp. 228-231 ${ }^{14}$ ).

sistemas de informações, etc.), tampouco da falta de recursos humanos para cuidar dos $16.866 \mathrm{~km}$ de fronteira terrestre.

14 Território como norma e território normado, do ponto de vista analítico, diferenciam-se. Na primeira situação o território é sujeito e na segunda é objeto da ação. De acordo com Santos (2004, p. 154): “Através de ações normadas e de objetos técnicos, a regulação da economia e a regulação do território vão agora impor-se com ainda mais força, uma vez que um processo produtivo tecnicamente fragmentado $\mathrm{e}$ geograficamente espalhado exige uma permanente reunificação, para ser eficaz. O aprofundamento resultante da divisão do trabalho impõe formas novas e mais elaboradas de cooperação e de controle. As novas necessidades de complementaridade surgem paralelamente à necessidade de vigiá-las, acompanhálas e regulá-las. Estas novas necessidades de regulação e controle estrito mesmo à distância constituem uma diferença entre as complementaridades do passado e as atuais".
Os portos secos são elementos também constituídos a partir da fragmentação do processo produtivo, daí a imposição de ações normadas, criações de mais objetos técnicos e mais regulação (da economia e do território). Destarte, "as novas necessidades de complementaridade surgem paralelamente à necessidade de vigiá-las, acompanhá-las e regulálas. Essas novas necessidades de regulação e controle estrito mesmo à distância constituem uma diferença entre as complementaridades do passado e atuais" (SANTOS, 2004, p. 232). A norma, portanto, decorre da imanência entre uso do território e configuração territorial, "determinantes de diferentes tipos de normas" (ANTAS JR., 2005, pp. 63-64).

Refletindo um pouco mais a respeito das normas durante o atual período histórico, podemos afirmar que sistemas normativos são elaborados para garantir a organização e a fluidez das trocas internacionais, mas, esse processo tem temporalidades (tempo de ocorrência) distintas em cada país. As normas incidem diretamente nos custos de circulação de mercadorias, especialmente na determinação dos tempos de rotação de capital.

O fenômeno mundial de interiorização das aduanas também chegou ao Brasil, sendo implantados no âmbito da RFB. Trata-se de uma dinâmica de caráter técnico-normativos voltada à fluidez territorial. Os nós aduaneiros são distribuídos estrategicamente pelos territórios nacionais para operacionalizar o controle dos fluxos de mercadorias. Entre os principais fixos responsáveis por este processo estão os portos secos.

No Brasil, os portos secos foram criados no início da década de 1970 sob o nome de Centrais Aduaneiras do Interior (CAls). A partir de maio de 1996, o nome mudou para Estações Aduaneiras do Interior (Eadi) já como recintos alfandegados de uso público. A denominação Porto Seco passou a ser utilizada oficialmente a partir de janeiro de 2003, com uma "remodelagem" do regulamento aduaneiro. Segundo a Instrução Normativa RFB no 1208, DE 04 DE NOVEMBRO DE 2011: 
I - porto seco, o recinto alfandegado de uso público, onde são executadas operações de movimentação, armazenagem e despacho aduaneiro de mercadorias e de bens de viajantes, sob controle aduaneiro; II - porto seco de fronteira, o recinto localizado em ponto de fronteira alfandegado ou em área contígua (...); Parágrafo único. 0 porto seco não poderá ser instalado na zona primária de portos e aeroportos alfandegados.

Esta concepção "oficial", por ora será apreendida, compreendendo o elemento jurídico como fundamental neste caso. Contudo, devemos fazer uma análise geográfica ${ }^{15}$. No Brasil, todos os portos secos possuem postos da RFB que executam os serviços aduaneiros sob sua responsabilidade, além do processamento de despacho aduaneiro de importação e de exportação (conferência e desembaraço aduaneiros). Sob a norma jurídica federal também é realizado o drawback, regime aduaneiro especial instituído em 1966, pelo Decreto Lei no 37, de 21/11/66, “consiste na suspensão ou eliminação de tributos incidentes sobre insumos importados para utilização em produto exportado". A estrutura incentiva as exportações, "pois reduz os custos de produção de produtos exportáveis, tornando-os mais competitivos no mercado internacional". Os portos secos, em muitos casos, possuem áreas climatizadas e refrigeradas; áreas segregadas para produtos químicos; posto do Ministério da Saúde; posto do Ministério da Agricultura e posto da Polícia Federal. Os serviços aduaneiros nos

\footnotetext{
${ }^{15} \mathrm{Um}$ porto seco é um terminal interior alfandegado, podendo ser intermodal ou não, estabelecido em ponto estrategicamente definido, com a capacidade jurídica para o controle aduaneiro. 0 principal objetivo é dar maior velocidade às entradas e saídas de mercadorias, contribuindo para a fluidez territorial, ao mesmo tempo em que há o controle sobre as riquezas que circulam em estado puro. Trata-se da contradição (dialética) entre a busca de fluidez territorial com controle fiscal" (SILVA JUNIOR, 2016, p. 92).
}

portos secos chegam a ser $30 \%$ menores que nos portos e $90 \%$ menores que nos aeroportos.

\subsection{OS NÓS ADUANEIROS E A SITUAÇÃO GEOGRÁFICA FRONTEIRIÇA DE FOZ DO IGUAÇU}

Foz do Iguaçu possui atualmente quatro nós aduaneiros:

- Ponto de fronteira com o Paraguai,

- Ponto de fronteira com a Argentina,

- Aeroporto internacional

- Porto seco.

Além desses nós, a RFB está presente na aduana do Paraguai e tem possui um posto fiscal no município de Medianeira. Outros órgãos compõem o que chamamos de estrutura aduaneira.

Na figura 5 (página seguinte), podemos visualizar toda essa estrutura do controle aduaneiro. No esquema comparece toda a infraestrutura da RFB e sua relação com os fluxos e a empresa Multilog, administradora do porto seco (comentaremos adiante), além da Empresa Brasileira de Infraestrutura Aeroportuária (Infraero) e instituições de fiscalização fitossanitária. 
FRANÇA, R.

USO DO TERRITÓRIO BRASILEIRO, CONTROLE ADUANEIRO EM REDE E SITUAÇÃO DO NODAL DE FOZ DO IGUAÇU-PR

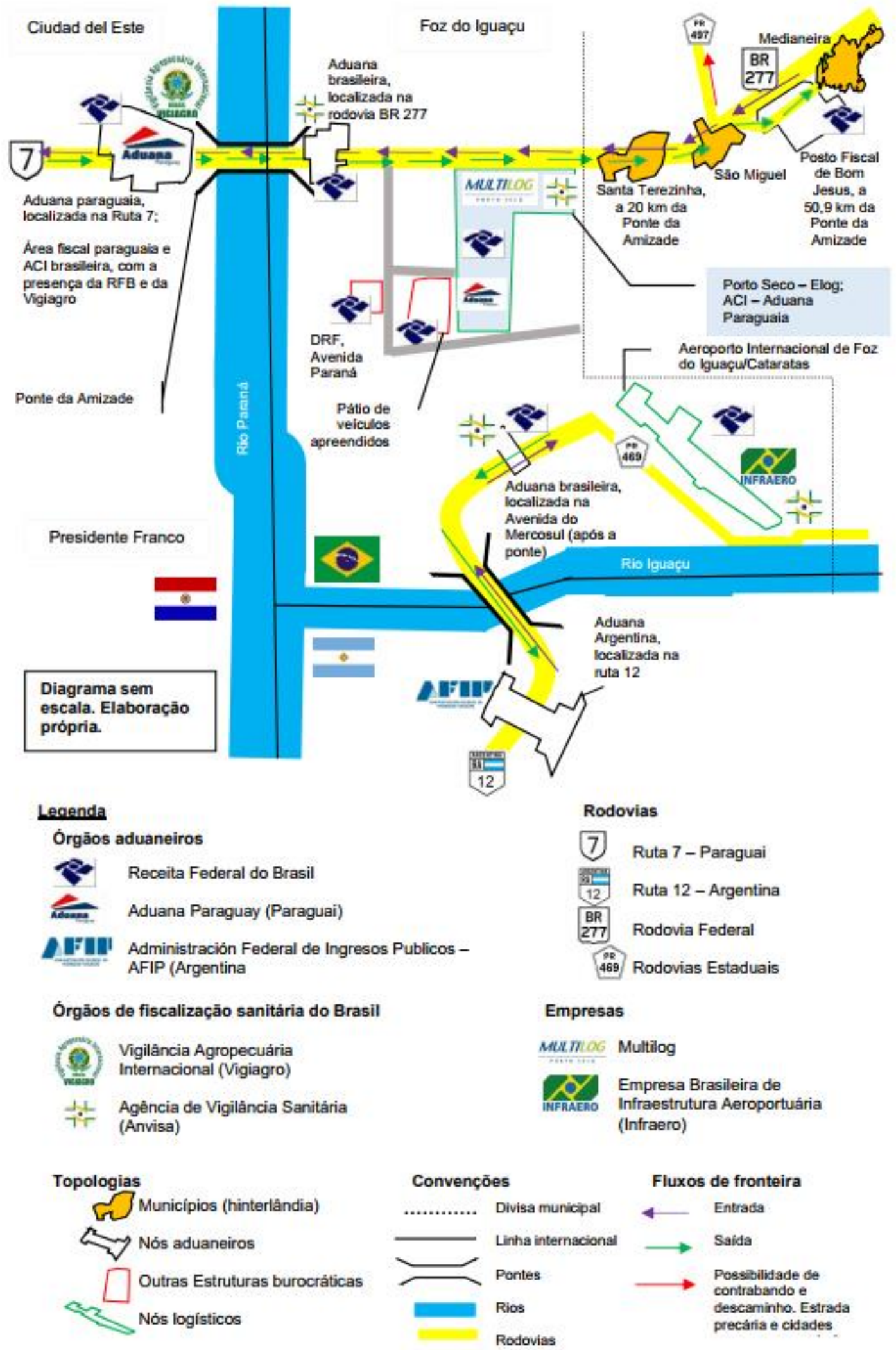

Figura 5 - Diagrama da Estrutura Aduaneira da RFB, 2016. Elaborado por Roberto França. 
Embora lindeira ao Rio Paraná, Foz do Iguaçu não tem função portuária em razão das condições histórico-geográficas, mas constitui-se como um grande carrefour ("intersecção"). Na perspectiva de Jean Brunhes (1962, p. 95), da intensificação dos fluxos e das ruas surge o carrefour, um espaço da "superfície terrestre que exprime essencialmente as trocas, e que constitui, inicialmente, o mercado local e, mais tarde, em um grande desenvolvimento, o campo da feira". Com esta premissa, Brunhes desenvolveu uma análise sobre situação geográfica.

A posição geográfica de Foz do Iguaçu, no sentido geométrico, centro da América do Sul e de três eixos do Iniciativa para a Integração da Infraestrutura Regional Sul-Americana - IIRSA (Eixos: Capricórnio, Hidrovia Paraguai-Paraná e Mercosul-Chile), também possibilitou a sua condução como centro geoestratégico para diversos projetos: energias renováveis; construção de um corredor ferroviário entre Antofagasta (Chile) e Paranaguá (Brasil); construção de um segundo porto seco; construção de uma segunda ponte entre Brasil e Paraguai; construção de um anel viário trinacional; universidade pública com seus projetos de integração da América Latina; implantação de uma Área de Livre Comércio $(A L C)$; implantação de uma Zona Franca (ZF); projeto de "segurança nacional" e gentrificação urbana (Projeto "Beira-Foz") entre outros. Com essas possibilidades, Foz do Iguaçu continuará por algum tempo como nodal estratégico e geopolítico, demandando estratégias de proteção e tributação de toda massa que circula na região.

A situação geográfica também pode ser compreendida a partir de Silveira (1999). De acordo com a autora, a situação derivaria da adjacência com diversos elementos motrizes e eventos que se materializam e se normatizam em um dado lugar. Para Silveira, a noção de evento em Milton Santos é basilar para a compreensão da situação geográfica. De acordo com Santos (2004, p. 93) “o lugar é o depositário final, obrigatório, do evento", a partir de um conjunto de possibilidades e da formação social.
Com duas grandes pontes ligando três países e integrando uma região de fronteira de quase um milhão de habitantes, considerando toda a aglomeração urbana. Portanto, trata-se de uma integração rodoviária de três municípios, originalmente separados pelas águas dos rios Paraná e Iguaçu, o que acabou dinamizando sistemas de controle aduaneiro de elevada densidade técnico-normativa (SILVA JUNIOR, 2015). A existência das duas pontes e da densa circulação nesse carrefour levou o estado brasileiro a construir uma aduana em cada ponte (e o mesmo fizeram Argentina e Paraguai). Cada ponto de fronteira é um nó aduaneiro (não necessariamente logístico).

O aeroporto internacional de Foz do Iguaçu é um dos nós aduaneiros, mas, ao contrário dos pontos de fronteira, também se configura como um nó logístico. O primeiro aeroporto de Foz do Iguaçu foi inaugurado em 1935. Em 1938, a Pan American World Airways (Pan Am) passou a operar, uma vez por semana, a linha internacional Rio-Assunção-Buenos Aires, com pouso em Foz do Iguaçu, e, na década de 1940 passou a ser pouso de uma linha do Correio Aéreo Nacional (CAN), que havia sido criado em 1941.

Esse aeroporto foi substituído por um aeroporto internacional em 1970 para suprir a demanda do turismo internacional. Este turismo internacional, associado à existência da zona franca de Ciudad del Este, faz com que este aeroporto tenha importante movimentação aduaneira. De acordo com Aeroportos do Brasil (2016), o terminal de cargas possui área total de $954 \mathrm{~m}^{2}$, sendo $450 \mathrm{~m}^{2}$ para importação e $54 \mathrm{~m}^{2}$ para exportação para realizar além destas duas operações, o trânsito aduaneiro (importação e exportação). Segundo a Infraero (2016), o aeroporto possui câmaras frigoríficas, armazém de carga perigosa (restrita), armazém de material radioativo e cofre. Somente neste ano de 2016, o aeroporto movimentou dentro dessa estrutura um total de $1.045,3$ toneladas, sendo 590,8 na exportação e 454,5 na importação. Entre os principais produtos importados estão: eletrônicos; cabelos; produtos para "pet shop"; 
fisioterapia; radioativos e hospitalares; peças para cooperativas; produtos de fiação. Os produtos mais exportados são: filé de pescados; amostras de carnes e aves; calçados (AEROPORTOS DO BRASIL, 2016).

O aeroporto e os dois pontos de fronteira são zonas primárias de grande movimentação de mercadorias e pessoas, com destaque para a segunda categoria, pois o principal concentrador de cargas da fronteira é o Porto Seco de Foz do Iguaçu, administrada pela empresa Multilog, que recém comprou a Elog , o nó logístico aduaneiro mais movimentado entre todos os portos secos da América Latina.

De acordo com a RFB, em 2015 passaram pelo Porto Seco de Foz do Iguaçu, 147.526 caminhões. As exportações despachadas chegaram a US\$ 2,8 bilhões (69.594 caminhões). O Paraguai representou o destino de $87 \%$ do volume, enquanto $13 \%$ das mercadorias foram para a Argentina. 0 Paraguai importou principalmente insumos e máquinas agrícolas, plásticos e tecidos. A Argentina importou papel e celulose, máquinas, veículos e preparações alimentícias diversas

Ao Brasil aportaram 77.838 caminhões para distribuir pelo território os seguintes produtos: Plásticos, grãos, sementes e cereais, do Paraguai; Malte, amidos e vinhos da Argentina; Produtos de horticultura, frutas, peixes, frutos do mar e vinhos do Chile. As importações despachadas no Porto Seco de Foz do Iguaçu atingiram US\$ 2 bilhões. Do volume total de cargas de importação que adentraram ao porto durante 2015, 56\% vieram do Paraguai, 38\% da Argentina e $6 \%$ do Chile. A RFB acusou um superávit comercial de US\$ 837 milhões, referente à diferença positiva entre as exportações e importações processadas no referido recinto aduaneiro.

O porto seco de Foz do Iguaçu tem uma área total de $150.000 \mathrm{~m}^{2}$, sendo $2.000 \mathrm{~m}^{2}$ de armazéns comuns; $3.300 \mathrm{~m}^{2}$ de armazéns químicos; 8 docas; 750 vagas de caminhões. Os serviços oferecidos no porto seco de Foz do Iguaçu são: armazenagem alfandegada (importação e exportação) - depósito alfandegado certificado; armazenamento geral; silo de $54 \mathrm{~m}^{3}$; depósito especial; atendimento especializado para cargas especiais; pátio para produtos químicos; câmara fria; entreposto aduaneiro; admissão temporária; exportação temporária; trânsito aduaneiro; drawback; operação 24 horas; gestão completa em segurança e scanner - redução em até $50 \%$ no tempo de permanência nos terminais. Este último é o principal responsável pelo aumento da fluidez no porto seco e aumento no número de liberações (SILVA JUNIOR, 2015).

Deste modo, nesta rede, o porto seco é uma estrutura aduaneira e logística voltada ao controle e à fluidez, que, no contexto da fronteira, por sua natureza jurídica públicoprivada, contribui para uma espécie de controle híbrido do território e das fronteiras.

O Estado normatiza os fluxos de comércio exterior e tributação, e, a empresa privada, por sua expertise competitiva, auxilia na atração dos fluxos ao porto seco, na medida em melhora os serviços e atendimento portuário dotando-o de mais técnicas. Embora os portos secos estejam alienados em relação à dinâmica urbana e social das cidades onde estão instaladas, esses espaços contribuem para a normatização territorial.

No contexto de fronteira trinacional também podemos mencionar o papel das Áreas de Controle Integrado $(\mathrm{ACl})$ no controle e fluidez dos despachos aduaneiros. As $\mathrm{ACl}$ foram estabelecidas na cidade de Recife, em 1993, por meio do MERCOSUL/CMC/DEC n. 5/93 (MERCOSUL, 1993), ficando convencionado como "Acordo para a aplicação dos controles integrados em fronteira entre os países do Mercosul" denominado "Acordo de Recife". De acordo com o Artigo I, alínea C da Decisão CMC 4/2000, a ACl é "parte do território do país sede, incluindo as instalações, onde se realiza o controle integrado por parte dos funcionários de ambos os países".

Brasil e Paraguai têm acordo e mantém $\mathrm{ACl}$ em ambos os países, mas este acordo não ocorre entre Brasil e Argentina (entre Foz do Iguaçu e Puerto Iguazu), pois a instalação e 
manutenção não é obrigatória. A opção de fazêlas depende da intensidade dos fluxos. No caso mais específico de Brasil e Paraguai o controle realizado é para acelerar os fluxos principalmente do agronegócio, no que tange à inspeção fitossanitária. O Brasil mantém uma $\mathrm{ACl}$ no Paraguai com a presença da Vigilância Agropecuária Internacional (Vigiagro) e RFB. O Paraguai, por sua vez, mantém uma $\mathrm{ACl}$ através da Aduana Paraguay.

Para finalizar a descrição dos nós aduaneiros e toda sua territorialidade-rede, mencionamos o Posto Fiscal Bom Jesus, localizado a 50,9 Km da Ponte da Amizade (linha internacional), no município de Medianeira, que serve para o combate ostensivo ao contrabando e descaminho, evidenciando ainda mais a característica policial do controle aduaneiro.

\section{CONSIDERAÇÕES FINAIS}

A fiscalização é um dos principais atributos do Estado, que por sua vez, estrutura redes de poder pelo controle da tributação, policiamento, inspeção e fiscalização, isto é, rede aduaneira responsável pelo domínio dos fluxos. Em uma das citações mais banalizadas sobre redes, podemos repetir a afirmação de Raffestin (1993, p. 204) de que a rede "faz e desfaz as prisões do espaço tornado território: tanto libera como aprisiona. É porque ela é 'instrumento', por excelência, do poder". O Estado, portanto, não poderia prescindir desse "desenho" de poder.

A título de revisão, o Estado brasileiro se utiliza de seu apanágio normatizador, regulador e controlador para dominar a circulação de pessoas, bens e serviços a fim de auferir tributos e proteger o território (não necessariamente os cidadãos). A rede aduaneira e fiscal organizada pelo Estado nacional acompanha a formação socioespacial brasileira e a rede urbana fortemente hierarquizada. Apesar de possuir pontos de fronteira com nós aduaneiros, apenas $4 \%$ do limite territorial é coberto pelos recursos humanos e tecnologias de controle.

Foz do Iguaçu apresenta-se, neste contexto, como um dos nodais estratégicos da circulação, concentrando fluxos lícitos e ilícitos, demandando estratégias aduaneiras e o estabelecimento de diversos nós aduaneiros, compondo uma estrutura com importante densidade técnica e normativa.

\section{REFERÊNCIAS}

ALVES, Giovanni. Dimensões da reestruturação produtiva: Ensaios de sociologia do trabalho. 2 ed. Londrina: Praxis; Bauru: Canal 6, 2007.

ANTAS JR., Ricardo Mendes. Território e regulação: espaço geográfico, fonte material e não-formal do direito. São Paulo: Humanitas, 2005.

BRAGA, Vanderlei. Logística e uso do território brasileiro: tipologia e topologia de nós logísticos e o projeto da plataforma multimodal de goiás (PLMG). Tese (Doutorado em Geografia). Campinas: Unicamp, 2013.

CHESNAIS, François. A mundialização do capital. São Paulo: Xamã, 1996.

- Mundialização: o capital financeiro no comando. In: Outubro. n. 5; v. 2; 2001.

DELEUZE, Gilles. Conversações: 1972-1990. São Paulo, Editora 34, 1992.

DIAS, Leila Christina. Redes: emergência e organização. In: CASTRO, Iná Elias de; GOMES, Paulo César da Costa; CORRÊA, Roberto Lobato (Orgs.). Geografia: conceitos e temas. Rio de Janeiro: Bertand Brasil, 1995. pp. 141-162.

BRASIL. RECEITA FEDERAL. Instrução Normativa SRF no 28. Disciplina o despacho aduaneiro de mercadorias destinadas à exportação. 1994. Disponível

em:<http://normas.receita.fazenda.gov.br/sijut2 consulta/link.action?visao=anotado\&idAto $=1344$ 8>. Acesso em jul. 2016.

\begin{tabular}{llll} 
& MINISTÉRIO & DA & INTEGRAÇÃO \\
\hline NACIONAL. & SECRETARIA & DE & PROGRAMAS
\end{tabular} REGIONAIS. PROGRAMA DE DESENVOLVIMENTO DA FAIXA DE FRONTEIRA. Proposta de Reestruturação do Programa de Desenvolvimento da Faixa de Fronteira. Brasília: Ministério da Integração Nacional, 2005. . INSTITUTO BRASILEIRO DE GEOGRAFIA

E ESTATÍSTICA (IBGE). Regiões de Influência das Cidades, 2007. 


\section{USO DO TERRITÓRIO BRASILEIRO, CONTROLE ADUANEIRO EM REDE E SITUAÇÃO DO NODAL DE FOZ DO IGUAÇU-PR}

PRESIDÊNCIA DA REPÚBLICA. CASA CIVIL. SUBCHEFIA PARA ASSUNTOS JURÍDICOS. Decreto no 6.759, de 5 de fevereiro de 2009 (a). Regulamenta a administração das atividades aduaneiras, e a fiscalização, o controle e a tributação das operações de comércio exterior. 2009 a. Disponível em: <http://www.planalto.gov.br/ccivil_03/_ato20072010/2009/decreto/d6759.htm>. Acesso em out. 2016.

MINISTÉRIO DA FAZENDA. RECEITA FEDERAL. Portaria MF no 125, de 04 de março de 2009 (b). Aprova o Regimento Interno da Secretaria da Receita Federal do Brasil - RFB Disponível em: <http://normas.receita.fazenda.gov.br/sijut2cons ulta/link.action?visao=anotado\&idAto=23482> Acesso em: jul. 2016.

MINISTÉRIO DA FAZENDA. RECEITA FEDERAL Instrução normativa RFB no 1208, de 04 de novembro de 2011. Estabelece termos e condições para instalação e funcionamento de portos secos e dá outras providências. Disponível em:

<http://normas.receita.fazenda.gov.br/sijut2cons ulta/link.action?idAto=36692\&visao=anotado $>$.

Acesso em: out. 2016.

MINISTÉRIO DA FAZENDA. RECEITA

FEDERAL. Portaria MF no 203, de 14 de maio de 2012. Aprova o Regimento Interno da Secretaria da Receita Federal do Brasil - RFB. Disponível em: <http://normas.receita.fazenda.gov.br/sijut2cons ulta/link.action?visao=anotado\&idAto=37965>.

Acesso em: jul. 2016.

INSTITUTO BRASILEIRO DE GEOGRAFIA

E ESTATÍ́sTICA (IBGE). Redes e fluxos do território. Gestão do território, 2014.

ESTUDOS TERRITORIAIS BRASILEIROS. O papel ativo da Geografia: um manifesto. In: BRANDÃO, Maria de Azevedo (Org.). Milton Santos e o Brasil. São Paulo: Perseu Abramo, 2004.

GOTTMANN, Jean. La politique des États et leur Géographie. Paris: Armand Colin, 1952.

HAESBAERT, Rogério. Território e multiterritorialidade: um debate. In: GEOgraphia.
a. IX, n. 17, 2007. Disponível em:

<http://www.uff.br/geographia/ojs/index.php/ge ographia/article/viewFile/213/20>

HUERTAS, Daniel. Território e circulação: transporte rodoviário de carga no Brasil. Tese (Doutorado em Geografia). Universidade de São Paulo, 2013.

JORNAL DO COMÉRCIO. Multilog finaliza compra da Elog Sul por R\$ 115 milhões. 06/10/2016. Disponível em: <http://jcrs.uol.com.br/_conteudo/2016/10/econ omia/525194-multilog-finaliza-compra-da-elogsul-por-r-115-milhoes.html>. Acesso em: 06/10/2016.

LIMA, Liana Maria Taborda; SÉLLOS-KNOERR, Viviane Coêlho de. A responsabilidade civil no caso de abuso de poder fiscal. In: Revista Jurídica. v. 4, n. 37, Curitiba: Unicuritiba, 2014. Disponível em:

<http://revista.unicuritiba.edu.br/index.php/RevJ ur/article/viewFile/1059/746>. Acesso em jul. 2016.

MERCOSUL - MERCADO COMUM DO CONE SUL. Acordo para a aplicação dos controles integrados em fronteira entre os países do Mercosul. Mercosul/CMC/DEC $n^{\circ}$ 5/93.

MERCOSUL - MERCADO COMUM DO CONE SUL. Acordo de Recife/CMC-DEC no 4/2000. Mercosul/CMC/DEC.

SACK, Robert David. Territorialidade humana: sua teoria e história. Cambridge: Cambridge University Press, 1986 (Tradução anônima disponível na internet diretamente do original Human territoriality: its theory and history).

SANTOS, Milton. A natureza do espaço: técnica e tempo. Razão e emoção. 4 ed. São Paulo: Edusp, 2004.

SILVEIRA, Maria Laura. O Brasil: território e sociedade no início do século XXI. 9 ed. Rio de Janeiro: Record, 2006.

SILVA JUNIOR, Roberto França. Circulação e logística territorial: a instância do espaço e a circulação corporativa. Tese (Doutorado em Geografia). Presidente Prudente: Unesp, 2009.

Circulação, epistemologia e a constituição de um ramo da ciência geográfica. In: Boletim Campineiro de Geografia. v. 2, n. 3, 2012 a, pp. 389-417. Disponível em: 
$<$ http://agbcampinas.com.br/bcg/index.php/bole tim-

campineiro/article/download/78/2012v2n3_RFra nca>. Acesso em: out. 2016.

Value chains and goods flow management in Brazil: reflections on territorial logistics. In: Terrae. v. 8, 1-2, 2012 b.

Fiscalizar com fluidez: o nó logístico aduaneiro de Foz do Iguaçu-PR e o uso corporativo do território. In: GeoUECE. v. 4, n. 7, jul-dez, 2015, pp. 88-102.

SILVEIRA, María Laura. Uma situação geográfica: do método à metodologia. In: Território, a. 4, n. 6, jan./jun. 1999.

SPOSITO, Maria Encarnação Beltrão. Introdução. In: SAQUET, Marcos Aurélio; SPOSITO, Eliseu Savério. (Orgs.) Território e Territorialidades: teorias, processos e conflitos. São Paulo: Expressão Popular, 2009. p. 11-16.

STEIMAN, Rebeca; MACHADO, Lia Osório. Limites e fronteiras internacionais: uma discussão histórico-geográfica. Terra Limitanea: Atlas da Fronteira Continental do Brasil. Rio de Janeiro: Grupo RETIS / CNPq / UFRJ, 2002.

UNITED NATIONS CONFERENCE ON TRADE AND DEVELOPMENT (UNCTAD). Handbook on the management and operation of dry ports. Genebra, 1991. Disponível em: <http://unctad.org/en/Docs/rdpldc7_en.pdf>.

Acesso em: 10 nov. 2012.

VALLAUX, Camille. El suelo y el Estado. Madrid: Daniel Jorro, 1914.

WORLD CUSTOMS ORGANIZATION (WCO). WCO Goals. Disponível em: $<$ http://www.wcoomd.org/en/about-us/what-isthe-wco/goals.aspx> 